\section{THE BIOLOGICAL INSTITUTE OF TIHANY, HUNGARY}

T HE Hungarjan Biological Research Institute is situated noar the village of Tihany on a small peninsula rupning out from the northern shore of Lake Balaton. It is about a hundred miles southwest of Badapest in an attractive position on the edge of the lake with wooded hills behind.

The Institute, founded in 1926, was well known before the War as the largest freshwater biological station in Europe; and the plant and animal life of the lake and its shores have been the subject of intensive study. The lake itself is fifty miles long, 6-9 miles wide and $10 \mathrm{ft}$. deep on the average; near Tihany the depth increases to about $30 \mathrm{ft}$.

During the War the Institute was fortunate in having suffered comparatively little material damage and has now become the main centre for biological research of all kinds in Hungary. With Dr. A. B. L. Beznak as director, accommodation has been afforded to workers who would otherwise have been deprived of facilities for research by the destruction of their laboratories in other parts of Hungary; in this manner an isolated residential community has been created of some seventy scientific workers, many of whom had earned international reputations before the War. The isolation is partly physical due to the present lack of transport, and partly scientific due to difficulties in maintaining contact with men of science in other countries ; in recent months institutions and individuals in Great Britain have been sending a certain amount of scientific literature which has been very gladly received and has helped to keep research going at the Institute.

The work of the hydrobiological department is directed by Dr. Bela Entz, assisted by Dr. Olga Sebestyen. Research is concerned mainly with limnological problems; in particular, investigations on organic detritus, on biocœnesis, on Cladocera, on phytoplankton and on sponges are being carried out or are projected.

Dr. J. Horvath is now working on soil fertility, sterility and exhaustion, and later intends to work on soil bacteriology.

Research in plant physiology is being carried out by L. J. Havas, mainly in relation to colchicine; he proposes to investigate effects of vegetable substances on animal tumours and pathogens.

Dr. L. Felföldi is concerned with plant geography and plant sociology; he is also interested in eytogenetics and hopes to study polyploid plants with a view to their practical applications.

Drosophila research is being done by Dr. G. Fabian, who has found and bred his own special stock. Present work is concerned with inheritance of fertility and sterility; it is later intended to work on the biochemistry of gene substances.

Work on the sociology of birds is carried out by Dr. N. Udvary, who studied bird life on the Hortobagy during the War.

Dr. S. G. Maltoltsy is investigating cell physiology and has recently been working on the hereditary effects of carcinogenic materials on Drosophila and on plants, and on the biological effects of ultra-violet rays.

Research on animal physiology is being done by the director, Dr. A. B. J. Beznak, by his wife, Dr. M. Beznak, and by Dr. I. Hajdu ; the work is mainly concerned with the physiological mechanism of the hyperglycæmia caused by the thrombosis or ligature of one of the heart vessels. The physiological mechanisms of heart hypertrophies and of suprarenal hypertrophies as well as the physiology of nutrition have also been studied by these workers.

Dr. T. Csaky plans to study the biochemistry of nutrition and also the production of protein foodstuffs for human and animal nutrition by the action of synthesizing agents such as yeast and nitrogenfixing bacteria.

Dr. A. G. B. Kovaes is concerned mainly with animal metabolism. $\mathrm{He}$ is now working on the physiological mechanism of the temperature response following histamine injections. In the future he wants to work on the part played by histamine in the central nervous system, and on surgical shock.

Dr. Zsuzsanna Rady works mainly on human nutrition, and after completing the results of a survey of nutritional conditions at the comparatively wealthy village of Valko, intends to carry out a similar research at the poorer village of Tihany. She hopes in this way to relate the needs of the population in a particular locality to the agricultural conditions of the country, and hence to make recommendations for the manner in which agriculture should be developed. At present she is working on the protein metabolism of fish, on fungal diseases in fish and on the bactericidal action of their skin secretions.

Biochemistry is represented by Dr. M. Gerendas, who is working at present principally on bloodclotting and the isolation and inactivation of thrombin and also (in collaboration with Prof. Szent-Györgyi) on muscle structure.

In addition to the researches mentioned above, work on organic (sterol) chemistry is being done by Dr. A. Kramli and on experimental animal psychology by Dr. M. Nagy.

\section{THERMODYNAMIC EQUILIBRIA OF HIG HER ORDER}

GOR two phas of the same substance to be in equilibrium, the thermodynamic potential, $G$,

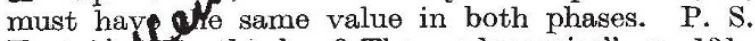
Epstein fTextbook of Thermodynamics", p. 131; 1936) hds suggested that, in order to derive the equilibrium conditions, the Taylor series for $G$ should be expanded to terms of high order. If, in this expansion, the $n$th order derivatives of $G$ are the lowest which have different values in the two phases, and all derivatives of lower order are equal in the two phases, then $d^{n} G^{\prime}=d^{n} G^{\prime \prime}$ is the condition for equilibrium of the $n$th order, where the symbols (') and (") indicate the separate phases. E. F. Lype (Phys. Rev., 69, 652; June 1946) has followed Epstein's suggestion and derived from the above condition the set of thermodynamic relations, which, in addition to the equivalence of the potentials, must hold for a system of a single substance which is in $n$th order equilibrium.

The relations for the equilibria of the first four orders, and the equations of the corresponding equilibrium curves, are examined in some detail. For a system in first-order equilibrium, the equation of the equilibrium curve is simply the ClausiusClapeyron equation. The transitions, between the two modifications of liquid helium, and between those of solid methane, have been interpreted as second-order equilibria. Adequate descriptions of the 